\title{
Action in Economics: Mathematical Derivation of Laws of Economics from the Principle of Least Action in Physics
}

\author{
Mr. Sayan Kombarov (Ecowatt LLP, Kazakhstan)
}

\begin{abstract}
The thesis of this paper is mathematical formulation of the laws of Economics with application of the principle of Least Action of classical mechanics. This paper is proposed as the rigorous mathematical approach to Economics provided by the fundamental principle of the physical science - the Principle of Least Action. This approach introduces the principle of Action into main-stream economics and allows to reconcile the main principles Austrian School of Economics with the laws of market, such Say's law, marginal value and interest rate theory, with the modern results of mathematical economics, such as Capital Asset Pricing Model (CAPM), game theory and behavioral economics. This principle is well known in classical mechanics as the law of conservation of action that governs any system as a whole and all its components. It led to the revolution in physics, as it allows to derive the laws of Newtonian and quantum mechanics and probability. Ludwig von Mises defined Economics is the science of Human Action. Action is introduced into Economics by the founder of Austrian School of Economic, Carl Menger. Production or acquisition of any goods, services and assets are results of purposeful acts in the form of expenditure of work and energy in the form of flow of money and material resources. Humans take them to achieve certain desired goals with given resources and time. Any economic good and service, financial, productive, or real estate asset is the result of such action.
\end{abstract}

\section{Definition of economic variables}

First of all, it is necessary to give mathematical definition of all economic goods, services and assets in the most general and abstract mathematical that can be consistently applied to the main relation of economic exchanges. That approach allows to derive and prove main laws of Economics, such as the law of marginal value.

Let us introduce the mathematical following definitions:

q - quantity of any good, service produced, productive, real estate or financial asset.

$\mathrm{p}$ - price of any such good, service or asset.

$\mathrm{v}$ - velocity of individual money stock $\mathrm{m}$.

In the same way, we define $\mathrm{Q}$ as macroeconomic goods, service and assets as a whole, whereas $\mathrm{V}$ is the macroeconomic velocity of money stock $\mathrm{M}$ with which they circulate in the Economy. $\mathrm{P}$ is the macroeconomic price level.

We must define each price and velocity in micro and macroeconomic form as the time differential of respectful quantity of $q$ and $m$ :

$\mathrm{p}=\mathrm{dq} / \mathrm{dt}$ and $\mathrm{v}=\mathrm{dm} / \mathrm{dt}$

$\mathrm{P}=\mathrm{dQ} / \mathrm{dt}$ and $\mathrm{V}=\mathrm{dM} / \mathrm{dt}$.

We must note that application of differential analysis to variables is justified, since we can assume that all microeconomic variables can be considered as infinitely small and continually changing with respect to their totals and cumulative values over long periods of time. The same note applies to macroeconomic variables. All economic variables are sufficiently great to assume that they are infinitely large, and their discrete quantities and corresponding prices are continuous over sufficiently long periods of time. That way we may define any price as the flow of economic benefits at a point in time. Velocity is monetary expression of the flow of economic benefits per unit of time at a certain moment.

\section{Application of economic variables in exchange equation and its consequences}

If we introduce these mathematical differential definitions into the exchange equations in macro and micro economic forms, $\mathrm{M} \times \mathrm{V}=\mathrm{P} \times \mathrm{Q}$.

This expression we can re-write as follows:

$\mathrm{M} \times \mathrm{V}=\sum \mathrm{m} \times \mathrm{v}=\sum \mathrm{p} \times \mathrm{q}=\mathrm{P} \times \mathrm{Q}$.

The sum of products of $p$ and $q, \sum p \times q$, can be understood as sum of microeconomic incomes or revenues, constituting macroeconomic Sales Revenue from the production and exchange of q quantity of various products and services at price $\mathrm{p}$.

Sales Revenue $=\mathrm{SR}=\sum \mathrm{p} \times \mathrm{q}$.

Then $\mathrm{P}$ is the macroeconomic price or value found as the total economic production value and sales revenue SR divided by the quantity total quantity of production and exchange volume Q: 
$\mathrm{P}=$ Sales Revenue $/ \mathrm{Q}$.

If we substitute $P=d Q / d t$ and $V=d M / d t$, then $M \times d M / d t=Q \times d Q / d t$.

$\mathrm{d}\left(\mathrm{M}^{2}-\mathrm{Q}^{2}\right) / \mathrm{dt}=0$ and $\mathrm{Q}=\mathrm{M}$. Its meaning is that macroeconomic money supply is equal to the supply of all goods, services, and assets. Money is always backed and can be exchanged into any asset, good or service and versa-versa.

$\mathrm{dM} / \mathrm{dt}$ is flow of money and $\mathrm{dQ} / \mathrm{dt}$ in the rate of productivity of economy.

The equation $\mathrm{dM} / \mathrm{dt}=\mathrm{dQ} / \mathrm{dt}$ means the equivalents of macroeconomic production and aggregates of money expenditure in the equation of the Gross Economic Product:

GDP $=$ Consumption + Saving + Taxes $=$ Government Expenditure + Private Consumption + Private Investment + Net export.

In the same way, the equation of exchange in microeconomic form invoking formulas $v=d m / d t$ and $p=d q / d t$, can be re-written in the following way:

$\sum \mathrm{m} \times \mathrm{v}=\sum \mathrm{m} \times \mathrm{dm} / \mathrm{dt}=1 / 2 \times\left(\sum \mathrm{dm}^{2} / \mathrm{dt}\right)=\sum \mathrm{p} \times \mathrm{q}=\sum \mathrm{q} \times \mathrm{dq} / \mathrm{dt}=1 / 2 \times\left(\sum \mathrm{dq}^{2} / \mathrm{dt}\right)$.

Here again we conclude that $\mathrm{m}=\mathrm{q}$ and $\mathrm{m} \times \mathrm{v}=\mathrm{p} \times \mathrm{q}$. It means that any good, service and asset is equivalent to money and can serve as a form of payment.

\section{Definition of Economic Action}

Both macroeconomic and microeconomic actions are defined in the same way as in classical mechanics as the product of "kinetic energy" of money and time dt summed in integral form for the whole period of time under consideration. Kinetic energy of money is the product of money M and its velocity V squared. Macroeconomic action $\mathrm{A}$ thus is the product of all microeconomic individual money $\mathrm{m}$ circulating and present in the economy and the macroeconomic money velocity $\mathrm{v}$ squared.

$$
\mathrm{A}=\int\left(\mathrm{M} \times \mathrm{V}^{2} / 2\right) \times \mathrm{dt} \text {. }
$$

Kinetic energy $\mathrm{K}$ of the whole macroeconomic system is the sum of all kinetic energies $\mathrm{k}$ of individual money stocks $\mathrm{m}$ comprising the system:

$$
\mathrm{K}=\mathrm{M} \times \mathrm{V}^{2} / 2=\sum \mathrm{k}=\sum \mathrm{m} \times \mathrm{v}^{2} / 2 \text {. }
$$

The macroeconomic system is moving in accordance with Koenig's theorem as if its whole mass of money M is concentrated in the single point of its center of gravity moving with the velocity of $\mathrm{V}$. Macroeconomic action is the sum of all microeconomic actions, defined as the product of individual money and the velocity of their circulation squared. In mathematical terms:

$$
\mathrm{A}=\sum \int\left(\mathrm{m} \times \mathrm{v}^{2} / 2\right) \times \mathrm{dt} \text {. }
$$

There are no potential forces in economics that can be expressed in mathematical terms involving and specific to variables q of economic goods, services and assets. All potential forces exerting humans to produce and spent money are invisible, in full compliance with the ideas of Adam Smith.

The conservation of Action that is represented as the sum of all various individual actions, resulting in creation of goods, services and assets from resources and materials, means that its variation is zero. These resources do not come into existence from void. This condition can be stipulated in the mathematical form as infinitely small variation of action being equal to zero: $\delta \mathrm{A}=0$.

Here symbol $\delta$ denotes infinitely small variation of the variable in front of which it stands.

Since, $\mathrm{M} \times \mathrm{V}=\mathrm{P} \times \mathrm{Q}$ and $\mathrm{V} \times \mathrm{dt}=\mathrm{dM}=\mathrm{dQ}$, then $\mathrm{A}=\int\left(\mathrm{M} \times \mathrm{V}^{2} / 2\right) \times \mathrm{dt}=\int(\mathrm{P} \times \mathrm{Q} \times \mathrm{V} / 2) \times \mathrm{dt}=\int(\mathrm{P} \times \mathrm{Q} \times \mathrm{dM}) / 2=$ $\int(\mathrm{P} \times \mathrm{Q} \times \mathrm{dQ}) / 2$.

Condition constancy of action means that its variation $\delta \mathrm{A}=0$, or that $\delta \int \mathrm{P} \times \mathrm{Q} \times \mathrm{dQ}=0$.

$\int(\mathrm{P}+\delta \mathrm{P}) \times(\mathrm{Q}+\delta \mathrm{Q}) \times \mathrm{dQ}-\int\left(\mathrm{P} \times \mathrm{Q} \times \mathrm{dQ}=\int(\mathrm{P} \times \mathrm{Q}+\mathrm{P} \times \delta \mathrm{Q}+\delta \mathrm{P} \times \mathrm{Q}+\delta \mathrm{P} \times \delta \mathrm{Q}-\mathrm{P} \times \mathrm{Q}) \times \mathrm{dQ}=0\right.$.

If we neglect the product of two infinitely small variables $\delta \mathrm{P}$ and $\delta \mathrm{Q}$, then the latter equation can be expressed as follows:

$$
\delta \mathrm{A}=\int(\mathrm{P} \times \delta \mathrm{Q}+\delta \mathrm{P} \times \mathrm{Q}) \times \mathrm{dQ}=\int \delta(\mathrm{P} \times \mathrm{Q}) \times \mathrm{dQ}=0 .
$$

Therefore, $\delta \mathrm{P} / \mathrm{P}=-\delta \mathrm{Q} / \mathrm{Q}$ and $\Delta \mathrm{Q} / \Delta \mathrm{P}=-\mathrm{P} / \mathrm{Q}$. Multiplying this expression with the product $\Delta \mathrm{P}^{2}$, we will find that $\Delta \mathrm{Q} \times \Delta \mathrm{P}=-\mathrm{P} \times \Delta \mathrm{P}^{2} / \mathrm{Q}$. If all variables $\mathrm{P}, \mathrm{Q}$ and $\Delta \mathrm{P}^{2}$ are greater, than zero, then $\Delta \mathrm{Q} \times \Delta \mathrm{P}<0$.

As this condition must hold over the whole range of changes $d Q$ in the macroeconomic variable $\mathrm{Q}$, that are not equal to zero, then we must conclude that $\delta(\mathrm{P} \times \mathrm{Q})=0$ and $\mathrm{P} \times \mathrm{Q}=$ Const or $\mathrm{P}=$ Const $/ \mathrm{Q}$.

Therefore, $\mathrm{M} \times \mathrm{V}=\mathrm{P} \times \mathrm{Q}=$ Const.

The equation $\mathrm{P}=$ Const/ $\mathrm{Q}$ is known in economics as the Law of marginal value. Total money supply $\mathrm{M}$ is equal to total supply of goods, services and assets $\mathrm{Q}$ with purchasing power Const/P that is equal to the supply of money. This equation gives us the prove of Say's law of market: 
$\mathrm{M}=$ Const $/ \mathrm{P}=\mathrm{Q}$.

Macroeconomic supply of money $\mathrm{M}$ is balanced by the demand for money supplied by the total macroeconomic volume or quantity of all goods, services, and assets Q.

In the same way we can deal with the sum of microeconomic actions:

$\delta \mathrm{A}=\delta \sum \int\left(\mathrm{m} \times \mathrm{v}^{2} / 2\right) \times \mathrm{dt}=0$

Substituting in the same way, as for macroeconomic equation of action, $p=d q / d t, m=d m / d t$ and $m \times v=p \times q$, we can find that $\delta \mathrm{A}=\delta \sum \int(\mathrm{p} \times \mathrm{q}) \times \mathrm{dq}=0$.

Since, all variables $\mathrm{q}$ are independent, therefore each $\mathrm{p}=$ Const $/ \mathrm{q}=\mathrm{m}$ and $\Delta \mathrm{q} \times \Delta \mathrm{p}<0$. This inequality explains so called Giffen's paradox, when increase in the price $\Delta$ p of the commodity q leads to the increase in purchases of and decline in the supply of q, so that $\Delta \mathrm{q}<0$.

Therefore, $\Sigma \Delta q \times \Delta p<0$. This expression is known as Hotelling's inequality. Laws of supply and demand of the market in the macroeconomic form are the same as in microeconomic form.

\section{Cantillon effect}

Since, $\mathrm{M} \times \mathrm{V}=\mathrm{P} \times \mathrm{Q}=$ Const, then $\mathrm{d}(\mathrm{M} \times \mathrm{V}) / \mathrm{dt}=\mathrm{d}(\mathrm{P} \times \mathrm{Q})=\mathrm{M} \times \mathrm{dV} / \mathrm{dt}+\mathrm{V} \times \mathrm{dM} / \mathrm{dt}=\mathrm{Q} \times \mathrm{dP} / \mathrm{dt}+\mathrm{P} \times \mathrm{dQ} / \mathrm{dt}$. Diving both parts of the equations by $M \times V$ and $P \times Q$, and multiplying by $d t$ we can find that $d M / M+d V / V=d P / P+d Q / Q$.

\section{Money as universal equivalent of action and whole market}

Having thus found the macro and microeconomic laws, we can re-formulate the macroeconomic action as follows:

$\mathrm{A}=\int\left(\mathrm{M} \times \mathrm{V}^{2} / 2\right) \times \mathrm{dt}=$ Const $\times \int \mathrm{dM}=$ Const $\times \int \mathrm{dQ}=$ Const $\times \mathrm{M}=$ Const $\times \mathrm{Q}$. Here we used equations, $\mathrm{M} \times \mathrm{V}=$ $\mathrm{P} \times \mathrm{Q}=$ Const, and $\mathrm{M}=\mathrm{Q}$.

In the same way, this macroeconomic action is equal to the sum of microeconomic actions:

$\mathrm{A}=\sum \int\left(\mathrm{m} \times \mathrm{v}^{2} / 2\right) \times \mathrm{dt}=\sum \mathrm{c} \times \mathrm{q}$. Here $\mathrm{c}$ are constants.

Therefore, we can see that each good, service and asset is result and equivalent of action and that Const $\times \mathrm{Q}=$ Const $\times \mathrm{M}=\sum \mathrm{c} \times \mathrm{q}=\sum \mathrm{c} \times \mathrm{m}$.

If we define money as constant commodity, that is not consumed and used in production of all other goods and services, then we can see that all material wealth in is equal to the sum of products of their quantities and constants or weight factors with which each valuable item contributes to the total value.

We can determine nominal or monetary Const in physical or commodity form as follows:

Const $=\$ X X X / Q$ and $c=\$ / q$.

Then we can see that individual constants are prices of all goods, services and assets.

\section{Action as money and Big Data}

Big data is the concept defined as the totality of all market information, pertaining to the quantities of all goods, services, and assets, present on the market. It also includes information on their prices and velocities with which they are created, exchanged, and consumed. Big Data is characterized as acronym $\mathbf{5 V}$, which stands for Variety, Volume, Velocity, Value and Veracity.

We can see that money chosen as universal equivalent of all goods, services and assets, has all characteristics of Big Data in terms of variety and variability in volume, velocity, quantity, value and price. Money must ensure veracity, completeness, and accuracy of data, so that its processing can result in efficient decision making.

\section{Labor theory of value}

Labor theory of value was firstly proposed by Adam Smith. In the previous sections we found that $\mathrm{p}=\mathrm{dq} / \mathrm{dt}$ and that $\mathrm{q}=\mathrm{c} / \mathrm{q}$. If we unite these equations into differential one, we can see that $\mathrm{q} \times \mathrm{dq}=\mathrm{c} \times \mathrm{dt}$. Integrating it from $\mathrm{t}=$ 0 , we can see that $\mathrm{q}^{2}=\mathrm{c} \times \mathrm{t}$. Here we assumed that $\mathrm{q}(0)=0$.

This equation can be expressed as $\mathrm{q}=\mathrm{c} \times \mathrm{t} / \mathrm{q}=\mathrm{c} \times \mathrm{p} \times \mathrm{t}$.

It can be interpreted that any good, service or asset is result of time or labor applied or incurred in value generating processes and capital producing its given quantity.

\section{Interest rate theory}

Let us define interest rate $\mathrm{R}$ as macroeconomic return in money terms on money existed and invested into production or spent for consumption or purchase of assets. We can understand it as inflow of additional incremental 
economic benefits dQ derived as value from production, consumption and investment to their previous existing stock or quantity:

$\mathrm{R}=\mathrm{dQ} / \mathrm{Q}$.

How do we determine the inflow of economic benefits dQ over a period of time dt?

$\mathrm{dQ}=\mathrm{P} \times \mathrm{dt}$.

Then, $\mathrm{R}=\mathrm{P} \times \mathrm{dt} / \mathrm{Q}$. Here $\mathrm{P}$ is $\sum \mathrm{p} \times \mathrm{q} / \mathrm{Q}$ is general price index or weighted average price of all goods, services and assets.

Time period dt can be replaced with any arbitrary time period $\mathrm{T}$ for which we seek interest rate. Therefore, we come to the following expression for interest rate:

$\mathrm{R} / \mathrm{T}=\mathrm{P} / \mathrm{Q}$.

Macroeconomic interest rate $\mathrm{R}$ is derived from the value of all goods, services and assets, not from an index of arbitrary bucket of commodities and services.

If we assume that $\mathrm{Q}$ is the quantity of gold, as universally accepted commodity money, then the interest rate formula $\mathrm{R}=\mathrm{P} \times \mathrm{T} / \mathrm{Q}$ explains Gibson's paradox, or inverse relationship of interest rates to the market price of gold.

If we express this equation as $\mathrm{Q}=\mathrm{P} \times \mathrm{T} / \mathrm{R}$, then we can see that it means that transactional or exchange value of money $\mathrm{Q}$ is equal to the discounted to perpetuity value in use of all market assets, goods and services, determined as the cash flow $\mathrm{dQ}=\mathrm{P} \times \mathrm{T}$, that is generated over the period of time $\mathrm{T}$.

If money is risk free relatively stable commodity, then $\mathrm{R}$ is risk-free rate of return. If investor holds such money $\mathrm{Q}$ that is equivalent to the value of the whole market, then his value in constantly increasing by the rate $\mathrm{R}$ per year.

Future value over the period of time $\mathrm{T}$ can be calculated as $\mathrm{Q}_{\mathrm{f}}=\mathrm{Q}+\mathrm{dQ}=\mathrm{Q} \times(1+\mathrm{R})$.

Future value over $n$ periods of time $\mathrm{T}$ is $\mathrm{Q}_{\mathrm{f}}=\mathrm{Q} \times(1+\mathrm{R})^{\mathrm{n}}$. Present value is $\mathrm{Q}=\mathrm{Q}_{\mathrm{f}} /(1+\mathrm{R})^{\mathrm{n}}$.

\section{Capital Asset Pricing Model (CAMP)}

This mathematical formalism can be used to build well-known theory of CAPM. If we re-write the interest rate equation as $\mathrm{R} \times \mathrm{Q}=\mathrm{R} \times \sum \mathrm{c} \times \mathrm{q}=\mathrm{P} \times \mathrm{T}$.

If each the quantity $\mathrm{q}$ of any product, such as goods, services or assets, $\mathrm{q}=\mathrm{c} \times \mathrm{t} / \mathrm{q}=\mathrm{c} \times \mathrm{p} \times \mathrm{t}$, then $\mathrm{P} \times \mathrm{T}=\mathrm{R} \times \sum \mathrm{a} \times \mathrm{p} \times \mathrm{t}$, where $\mathrm{a}=\mathrm{c}^{2}$ are also some arbitrary constants.

We can define $r$ as the yield of return of product q. It is the mathematical product of multiplication of $\mathrm{R}$ and $\mathrm{c}$ :

$\mathrm{r}=\mathrm{R} \times \mathrm{c}$. Factor $\mathrm{c}$ can be understood as the $\beta$-coefficient of congruence of industry or asset specific return $\mathrm{r}$ and the whole market return R. $\beta$ is well-known correlation coefficient of systematic risk measuring correlation of the risks and rewards associated with asset $\mathrm{q}$ and the whole market, represented by the commodity $\mathrm{Q}$, that is equivalent to it.

Then, $\mathrm{R} \times \mathrm{Q}=\sum \mathrm{r} \times \mathrm{q}$.

Then we can define return or yield of any asset as $Y=R+\beta \times(r-R)$.

\section{Information as entropy. Binary formula of information.}

Interest rate $\mathrm{R}$ can be regarded as the quintessence of all market prices of goods, services and assets. Bearing in mind that $\mathrm{P}=\mathrm{dQ} / \mathrm{dt}$, formula for market interest rate $\mathrm{R}$ can be transformed in the following way:

$\mathrm{R}=\mathrm{P} \times \mathrm{T} / \mathrm{Q}=\mathrm{T} \times(\mathrm{dQ} / \mathrm{dt}) / \mathrm{Q}=\mathrm{T} \times \mathrm{dln}(\mathrm{Q}) / \mathrm{dt}$.

Integrating it over time 0 to $t$, assuming $R$ and $T$ are fixed, we can see that $R=(T / t) \times \ln [Q / Q(0)]$, where $\ln x$ is natural logarithm $\mathrm{x}$ with base $\mathrm{e}=2.71 \ldots$

If $\mathrm{t}=\mathrm{n} \times \mathrm{T}$, then $\mathrm{R}=(1 / \mathrm{n}) \times \ln [\mathrm{Q} / \mathrm{Q}(0)]$. This formula mathematically equivalent to Boltzmann's formula for entropy $\mathrm{S}=\mathrm{k} \times \ln \mathrm{W}$, where $\mathrm{k}-$ Boltzmann's constant and $\mathrm{W}$ is probability of system's configuration. This formula can be transformed into Shannon's formula for quantity of information measurement.

If we denote $g=\log _{2} \mathrm{e}$, or logarithm of e with the base of 2 , then we can find that $\mathrm{Q} / \mathrm{Q}(0)=2^{\mathrm{R} \times \mathrm{n} \times \mathrm{g}}$

$\mathrm{Q}(\mathrm{t})$ is the number that can be expressed in a very large binary form.

\section{Mean quantities and Gaussian probability}

As we have found, total value of market assets, goods and services is equal $\mathrm{Q}=\sum \mathrm{c} \times \mathrm{q}$.

Each $\mathrm{q}$ is found as integral $\mathrm{dq}$ and $\mathrm{p}=\mathrm{dq} / \mathrm{dt}$ over time:

$\mathrm{Q}=\int \mathrm{dQ}=\int \mathrm{P} \times \mathrm{dt}$.

$\mathrm{q}=\int \mathrm{dq}=\int \mathrm{p} \times \mathrm{dt}$. 
If $\mathrm{R}$ and $\mathrm{T}$ are constants, $\mathrm{Q}=\mathrm{Q}(0) \times \exp (\mathrm{R} \times \mathrm{t} / \mathrm{T})$ and $\mathrm{P}=$ Const $/ \mathrm{Q}=$ Const $\times \exp (-\mathrm{R} \times \mathrm{t} / \mathrm{T})$.

If $\mathrm{Q} \times \mathrm{dQ}=$ Const $\times \mathrm{dt}, \mathrm{q} \times \mathrm{dq}=\mathrm{c} \times \mathrm{dt}$ and $\mathrm{q}^{2}=\mathrm{c} \times \mathrm{t}$, then $\mathrm{Q}=<\mathrm{Q}>=\int$ Const $\times \exp (-\mathrm{R} \times \mathrm{t} / \mathrm{T}) \times \mathrm{dt}=\int \mathrm{Const} \times \exp (-$ Const $\left.\times \mathrm{Q}^{2}\right) \times \mathrm{Q} \times \mathrm{dQ}=\sum \mathrm{c} \times \int \exp \left(-\right.$ const $\left.\times \mathrm{q}^{2}\right) \times \mathrm{q} \times \mathrm{dq}=\sum \mathrm{c} \times<\mathrm{q}>.<\mathrm{Q}>$ and $<\mathrm{q}>$ are weighted averages found by integrating $\mathrm{q}$ with normal or Gaussian density of probability function.

Here we also assumed that each $\mathrm{p}=\mathrm{dq} / \mathrm{dt}=$ const $/ \mathrm{q}=$ const $\times \exp (-\mathrm{r} \times \mathrm{t} / \mathrm{T})=$ const $\times \exp \left(-\operatorname{const} \times \mathrm{q}^{2}\right)$.

We must note, that as is well-known, Gaussian probability function is result of binominal distribution function with large infinitely small variables, as the number of quantities and prices that can be assumed as varying continuously, not as discrete quantities.

\section{Learning process or curve}

We can find the total utility of all goods, services and assets as the integral:

$\mathrm{Q}=\sum \mathrm{c} \times \int \mathrm{dq}=\sum \mathrm{c} \times \int \mathrm{p} \times \mathrm{dt}=\sum \int \mathrm{const} \times \mathrm{dt} / \mathrm{q}$. Here $\mathrm{p}=\mathrm{const} / \mathrm{q} . \mathrm{q}=\mathrm{q}(0) \times \exp (\mathrm{r} \times \mathrm{t} / \mathrm{T})$, where $\mathrm{r}=\mathrm{dq} / \mathrm{q}-$ return on asset, good and service purchases defined as inflow of additional economic benefits dq arising as result of value in use derived from them.

Assuming that $\mathrm{r}$ and $\mathrm{T}$ as the unit of time are constants, we can find $\mathrm{Q}$ after integration from 0 to $\mathrm{t}$ as follows:

$$
\mathrm{Q}=\sum(\text { const } \times \mathrm{T} / \mathrm{r}) \times[1-\exp (-\mathrm{r} \times \mathrm{t} / \mathrm{T})] \text {. }
$$

This is the function of utility of prospect theory and the theory of household savings. Note, that $r$ is the weight of the utility function in prospect theory. The higher it is, the lower the standard deviation from the mean of the normal probability distribution function and uncertainity of decisions.

\section{Game theory}

Having found total utility function as $\mathrm{Q}=\sum($ const $\times \mathrm{T} / \mathrm{r}) \times[1-\exp (-\mathrm{r} \times \mathrm{t} / \mathrm{T})]$, where $\mathrm{r}$ and $\mathrm{T}$ are constants, we can substitute $\mathrm{t}=\mathrm{c} \times \mathrm{q}^{2}$ as we found previously, where $\mathrm{c}$ is also a constant, we can see that total utility depends on the gaussian probability:

$\mathrm{Q}=\sum($ const $\times \mathrm{T} / \mathrm{r}) \times\left[1-\exp \left(-\mathrm{c} \times \mathrm{q}^{2}\right)\right]$. If $1=\sum \operatorname{probability}(\mathrm{q})$, then outcome of strategy determining $\mathrm{q}$ is dependent on the probabilities of strategies of all other products and services.

The Gaussian probability function is as well-known as the extreme case of binominal probability.

\section{Uncertainty principle and subjectivity of prices}

As we found that probability of $\mathrm{Q}$ is normally distributed, and that price or value $\mathrm{P}$ is inversely related to quantity $\mathrm{Q}, \mathrm{P}=$ Const/ $\mathrm{Q}$, then it can be shown that probability of $\mathrm{P}$ is also normally distributed and that product of errors $\Delta \mathrm{P}$ and $\Delta \mathrm{Q}$ calculated as square root of standard deviation of $\mathrm{Q}$ and $\mathrm{P}$ from their averages $<\mathrm{Q}>$ and $<\mathrm{P}>$ is also constant:

$\Delta \mathrm{Q} \times \Delta \mathrm{P}=$ Const.

Here constants are related to some economic resource constants specific to the market conditions under review.

The same relationship holds between the errors or spreads of quantity q of any good, service or asset and its price:

$$
\Delta \mathrm{q} \times \Delta \mathrm{p}=\text { Const. }
$$

This uncertainty principle is governing as self-correcting market mechanism as result of gradual accumulation of a large number of errors that suddenly and unexpectedly lead to a rapid and large fall of market prices after they reach certain maximum.

Then, final equation for macroeconomic price $\mathrm{P}$ can be expressed as follows:

$$
\mathrm{P}=\mathrm{C} / \mathrm{Q} \pm \Delta \mathrm{P}=\mathrm{C} / \mathrm{Q} \pm \mathrm{C} / \Delta \mathrm{Q} . \mathrm{C}=\text { Const. }
$$

Same relationship is valid for the price of any good, service or asset:

$\mathrm{p}=\mathrm{c} / \mathrm{q} \pm \Delta \mathrm{q}=\mathrm{c} / \mathrm{q} \pm \mathrm{c} / \Delta \mathrm{q} . \mathrm{c}=$ const.

The economic meaning of these equations is that any price cannot be mathematically precisely calculated or determined by a party or observer outside the parties of the transaction. Price is subjective and cannot be fixed without creating another uncertainty. Errors from such arbitrary fixation will be gradually accumulating and eventually can result in an even greater unpredictable outcome in price or quantity. 


\section{Ergodic invariant and price stability}

How is it possible to achieve price stability? Previously, we found that Const $\times \mathrm{Q}=$ Const $\times M=\sum \mathrm{c} \times \mathrm{q}=\sum \mathrm{c} \times \mathrm{m}$. Macroeconomic constant $\mathrm{C}$ and microeconomic constants $\mathrm{c}$ are coefficients between corresponding prices and quantities:

$\mathrm{P}=\mathrm{C} / \mathrm{Q}$

$\mathrm{p}=\mathrm{c} / \mathrm{q}$.

These equations are of course subject to certain bias or error as explained in the previous section.

The market interest rate $\mathrm{R}$ is related to time $\mathrm{T}$ for which it is determined as follows:

$\mathrm{R} / \mathrm{T}=\mathrm{P} / \mathrm{Q}$. Here $\mathrm{P}$ is macroeconomic price level or price index of the whole market, $\mathrm{P}=\sum \mathrm{p} \times \mathrm{q} / \mathrm{Q}$.

We can consider $\mathrm{Q}$ as the universal equivalent or commodity money and the total wealth created in the form of all goods, services and assets. The sum of mathematical products all such goods, services and assets, is equal to Q:

$\mathrm{Q}=\sum \mathrm{c} \times \mathrm{q} / \mathrm{C}=\sum \mathrm{c} \times \mathrm{m} / \mathrm{C}$.

Then, the expression $\mathrm{R} \times \mathrm{Q}=\mathrm{T} \times \mathrm{P}$ can be expressed as follows:

$\mathrm{R} \times\left(\sum \mathrm{c} \times \mathrm{q} / \mathrm{C}\right)=\mathrm{T} \times\left(\sum \mathrm{p} \times \mathrm{q} / \mathrm{Q}\right)$.

Here $\mathrm{c}$ and $\mathrm{C}$ are constants.

Then, if we assume that $\mathrm{C}=\mathrm{Q}=$ Const, then $\mathrm{c}=\mathrm{p}=$ const. All prices will also be constants, if $\mathrm{R}$ is constantly related to certain time period $\mathrm{T}$, or if $\mathrm{R} / \mathrm{T}$ is constant.

If we assume that $\mathrm{R}$ is the rate of wealth creation, that can be considered as inflow of incremental goods, services and assets $d Q$ over the period of time $T$, and such rate of return $R=d Q / Q$ is constant throughout a period of time $\mathrm{T}$, then all prices $\mathrm{p}$ must be constant.

Macroeconomic demand $\mathrm{P}=$ Const/Q must be equal to the macroeconomic supply curve $\mathrm{P}=\mathrm{R} \times \mathrm{Q} / \mathrm{T}=\mathrm{R} \times \mathrm{Q} \times \mathrm{F}$, where $\mathrm{F}=1 / \mathrm{T}$, or frequency of all economic exchanges that are taking place over the period of time $\mathrm{T}$.

Therefore, in order to stabilize prices, we must define macroeconomic money supply $\mathrm{M}$ as the macroeconomic quantity of commodity money $Q$ the annual rate of increase or inflow $\delta Q$ of which in quantitate terms is very small in relation to its existing stock Q. Gold is such commodity traditionally and historically played role of universal money and equivalent of all wealth of civilization. Such rate of increase for gold is equal to $2 \%$ per year, which is very small and can be considered as negligible and accounting to its small dissipation and loss.

Constants $\mathrm{C}$ and c actually have nominal value $\$$ in terms of commodity money.

Constant relationship of $\mathrm{Q} / \mathrm{T}$ is called centennial or ergodic invariant.

\section{The gravitational model of economic forces}

We can assume that the whole economic system is similar to the solar system. To an outside observer, whose system of coordinates is fixed, our macroeconomic system is similar to a body of all goods, services and assets, comprising is, as a whole, is in translation motion versus it. Its whole is acting as a point with the mass concentrated in the center of gravity of our economic system with the mass of money $\mathrm{M}=\mathrm{Q}$, where $\mathrm{Q}$ is the quantity of commodity money equivalent to the total economic wealth. All other assets, goods and services are rotating around common center of gravity with mass $\mathrm{M}=\mathrm{Q}$, that is equivalent to total wealth of the global economy.

If we consider this motion from that center of gravity, then we can regard all assets, goods and services giving yield $r=\beta \times R$, as rotating at a certain distance around $r$ it with certain time period $t$.

Interest rates $\mathrm{R}$ and $\mathrm{r}$ here are playing role of analogues of radii of planet motion around the Sun.

The velocity of such circulation $\mathrm{V}=\mathrm{P}=\mathrm{Q} \times \mathrm{R} / \mathrm{T}$. It is equal to the weighted average of velocities of goods, services and assets:

$\mathrm{V}=\mathrm{P}=\left(\sum \mathrm{p} \times \mathrm{q}\right) / \mathrm{Q}=\left(\sum \mathrm{v} \times \mathrm{q}\right) / \mathrm{Q}=\left(\sum \mathrm{c} \times \mathrm{q}\right) / \mathrm{C}$, where $\mathrm{c}=$ const and $\mathrm{C}=$ Const.

This equation means, that the macroeconomic velocity $\mathrm{V}$ of money $\mathrm{M}$ circulating in the economy is equal to the sum of all velocities $\mathrm{v}$ of all money masses $\mathrm{m}$ that together compose it. If $\mathrm{C}=\mathrm{Q}=\mathrm{Const}$, then all $\mathrm{p}$ and $\mathrm{v}$ are also constants. The whole system is evenly rotating around the center of its gravity.

If we find centripetal acceleration $\mathrm{A}$ of such rotation, it must be as follows:

$\mathrm{A}=\mathrm{V}^{2} / \mathrm{R}=\mathrm{Q}^{2} \times \mathrm{R}^{2} / \mathrm{T}^{2} / \mathrm{R}=\mathrm{Q}^{2} \times \mathrm{R} / \mathrm{T}^{2}$.

According to the law of universal gravitation, $A=(G \times M) / R^{2}$, where $G$ is gravitational constant. Here $M$ is the mass of gravity of Sun or the macroeconomic mass of money stock of the whole macroeconomic system.

If we equalize both latter expressions for $A$ as follows, we can find: $A=(G \times M) / R^{2}=Q^{2} \times R / T^{2}$.

Then we can find that $R^{3} / T^{2}=G \times M / Q^{2}$. 
If we define macroeconomic money supply $\mathrm{M}$ as the constant volume of commodity money $\mathrm{Q}$, then we can see that $\mathrm{R}^{3} / \mathrm{T}^{2}=\mathrm{G} / \mathrm{Q}$.

$$
\mathrm{Q}=\text { Const } / \mathrm{P} \text {. }
$$

Then Const $\times \mathrm{P}=\mathrm{R}^{3} / \mathrm{T}^{2}$.

If $\mathrm{P}$ is constant with exception of uncertainties $\Delta \mathrm{P}$, then $\mathrm{R}^{3} / \mathrm{T}^{2}$ is constant. This expression is known as third Kepler's law of orbital planetary motion around the Sun.

If $\mathrm{P}$ is constant, then for any good, service or asset, $\mathrm{R}=\mathrm{c} \times \mathrm{r}, \mathrm{T}=\mathrm{c} \times \mathrm{t}$, where $\mathrm{c}$ are coefficients of correlation of goods, services and assets with the market as the whole, then Const $\times P=\operatorname{const} \times r^{3} / t^{2}$.

Periods of rotation $t$ and interest rates $r$ for each class of assets, goods and services are constants. It also means, that similar national economics, industries and companies tend to dynamically rotate close to each other around common center of gravity and force forming regional economies, clusters and vertically integrated combinations that rotate on the same economic orbit. They are also mutually attracting each other in accordance with the law of universal gravity proportional to their respective masses, divided by square of the difference in interest rate.

That theory is known as gravity model of international trade developed by Jan Tinbergen and Walter Isard.

\section{Conclusion/Summary}

The paper is aimed to define action in Economics in the same way as in classical mechanics and physics. It introduces definitions of money velocity and price as time differentials of the respected quantities of money and services, goods, assets. Action is defined as exchange or expenditure of money as kinetic energy resulting to acquisition of any asset class. Action is exchange of money or generation of money flow. Assets, goods and services are the result of conversion and rational expenditure of everyone's scarce resources, such as energy, work and time into action to produce and consume. The nature of action is thus fundamental for Economics.

This approach from the basic principle of Least Action allows to consistently define or model mathematically virtually all results of Economics and Finance achieved so far.

\section{References}

- Ludwig von Mises. Human Action.

- Adam Smith. Wealth of Nations.

- Econophysics. Background and Applications in Economic, Finance and Sociophysics. Edited by Gheorghe Săvoiu, Ion Iorga Simăn.

- Econophysics: from Game Theory and Information Theory to Quantum Mechanics Edward Jimeneza, Douglas Moyad.

- J. T. Manhire. The Action Principle in Market Mechanics.

- Paul A. Samuelson. Maximum Principles in Analytical Economics. Nobel Memorial Lecture. 1970.

- $\quad$ M. F. Osborne, The Stock Market and Finance from a Physicist's Viewpoint, Crossgar Press, 1977.

- P. Mirowski, Physics and the Marginalist Revolution, Cambridge J. Econ. 8 (1984) 361.

- $\quad$ R. Landauer, Information Is Physical, Physics Today 44 (1990) 23.

- Sayan Kombarov. 2021. Energy of Human Action. 